\title{
Trends, Changes, Challenges in North American (Eurocentric) Psychology: Rethinking Assumptions, Practices, and Organization in Socio-Political Contexts
}

\author{
Anthony J. Marsella \\ Professor Emeritus, University of Hawaii
}

\section{Preface}

Psychology is neither the property, nor possession, of the American Psychological Association (APA), or any of its related organizations! Psychology is not a "commodity" to be bought, owned, and/or distributed by any organization or institution, even as that organization or institution may seek to control its existence, definition, and standardization, or other uses through wealth, position, and person. Psychology is not to be used to establish "hegemony," by imposing an organization or institution's expressed purposes, or empowering an organization or institution's implicit and explicit assumptions, goals, and intentions. The use of regulation, by-laws, and other forms of privileged, legal, or unexpressed codification, including membership demographics, must be clear in their intent and purpose. Nor should psychology be driven in its purposes by political or ideological preferences, designed to favor one nation's pursuit of hegemonic control.

Because of the political, economic, and military status and stature of the United States of America, the American Psychological Association has distinct advantages in propagating and enforcing its unique historical, cultural, and epistemological assumptions and practices both within the nation, and across the world. This propagation does not represent an illegal act, but it does constitute a critical moral and ethical issue because of APA levels of proportion, process, and ideology. When psychology is organized and institutionalized within a powerful corporate model, it has the potential to serve obsequious purposes for "colonizing mind," via its assumptions, methods, and accepted standards. This situation has been described by many nonWestern scholars, and deserves the courtesy and respect of the APA, North American, and Eurocentric psychologies: 
The current Western thinking of the science of psychology in it prototypical form, despite being local and indigenous, assumes a global relevance and is treated as a universal mode of generating knowledge. Its dominant voice subscribes to a decontextualized vision with an extraordinary emphasis on individualism, mechanism, and objectivity. This peculiarly Western mode of thinking is fabricated, projected, and institutionalized through representation technologies and scientific rituals and transported on a large scale to the non-Western societies under political-economic domination. As a result, Western psychology tends to maintain an independent stance at cost of ignoring other substantive possibilities from disparate cultural traditions. Mapping reality through Western constructs has offered a pseudo-understanding of the people of alien cultures and has had debilitating effects in terms of misconstruing the special realities of other people and exoticizing or disregarding psychologies that are non-Western. Consequently, when people from other cultures are exposed to Western psychology, they find their identities placed in question and their conceptual repertoires rendered obsolete (Misra, 1996, 497-498).

In other words, psychology does not belong to a nation, culture, group, or organization. It is a powerful frame-of reference - a body of knowledge - a construction of reality -capable of abuse when its particular assumptions, principles, and practices are used for questionable purposes. The reality of the present "hegemonic" situation and impulse presents many challenges and risks for psychology as an unbounded body of knowledge. Whether or not it is organized as a formal (institutionalized) discipline, profession, "science," or "folk" way-of-knowing and inquiry, psychology must not become owned or dominated by concentrated organizational, national, or international powers and forces. Psychology is much too important as a boundary-less body of knowledge, offering unlimited opportunities rather than a political or moral empowered construction of reality. For this, ultimately, in my opinion, is an essential function of psychology across the world - the social and cultural construction of reality within lived contexts (e.g., Berger \& Luckman, 1966; Huntington, 1996/2011).

Much as we are witnessing the uses of military, political, economic, and cultural forces for hegemonic control and dominance, it would be well for us to grasp the potential uses of psychology as an effort after control and dominance of a group, organization, or nation. Psychology carries with it implicit and explicit power asymmetry possibilities. It can easily be "weaponized" without an obvious and apparent identification of its purposes. In doing so, the pursuit of "homogenization" occurring nationally, and around the world, suggests psychology is a powerful body of knowledge (Marsella, 2014).

The importance of diversity and variation is obvious, although history is replete with examples of societies seeking to homogenize members according to the values and priorities of those in power. For example, recall the many efforts to take children away from indigenous people, sterilize those deemed less fit mentally or physically, and its 
ultimate manifestations in genocides and ethnic cleansings. Who chooses what and how psychology will be used to pursue preferred ends?

Today, we are faced with an epic global struggle between homogenization and diversity. The powerful influences of American and Western European culture serve as a colonizing force for human thought content and process -- a "colonization of mind." The pressures for uniformity and homogenization destroy the very foundations of diversity so essential as a characteristic and resource for life. The fundamental issue of human identity, encoded in beliefs, attitudes, and other content constructions of "reality," must be understood as a detriment to life, especially in the face of the massive destruction occurring across the world to natural resources and to macro and micro social patterns of sustaining life (e.g., Marsella, 2014).

In this paper, I call attention to the trends, changes, and challenges facing North American psychology, and the risks of the institutionalization of psychology within organizations, associations, and agencies capable of power and influence abuses. It is essential we become alert to the menacing overt and covert (often insidious) efforts to pursue power and influence in the cause of "knowing" what is right, and insisting others conform to your views, under threat of insult, affront, and derision.

I do not wish to deny any individual, group, organization, association, institution, or other collective identity, the right to hold their views. I do, however, encourage any of these collectives to grasp the historical and cultural context in which they exist, to reveal their assumptions and position, and to alert everyone to their efforts. I also am compelled to warn all of us of the risks when any of individual collectives acquire the power to limit and restrain others. It is about freedom! It is about justice! Is not justice sacrificed when fairness is forgotten in pursuit of special interest goals and powers? International meetings, organized and conducted, and influences for purposes of standardization of any group's or nation's favored "psychology," constitutes a risk and threat to knowledge and the virtues of diversity.

\section{Changes, Trends, Challenges ... .}

In the past three decades, North American (Eurocentric) Psychology has experienced profound changes and challenges to its identity, directions, and institutional organization as a discipline and profession. I have categorized these changes into seven areas for purposes of discussion: (1) demographic, (2) conceptual, (3) technical, (4) socio-political, (5) training, (6) content, and (7) topical priorities. The categories are arbitrary! It is possible to condense or elaborate them based on preferences and/or purposes. Chart 1 offers a graphic display of these categories and their exemplar contents. In my opinion, it is essential to recognize the many trends, changes, and challenges as efforts are made to rethink the APA and related organizations. Context is critical! 


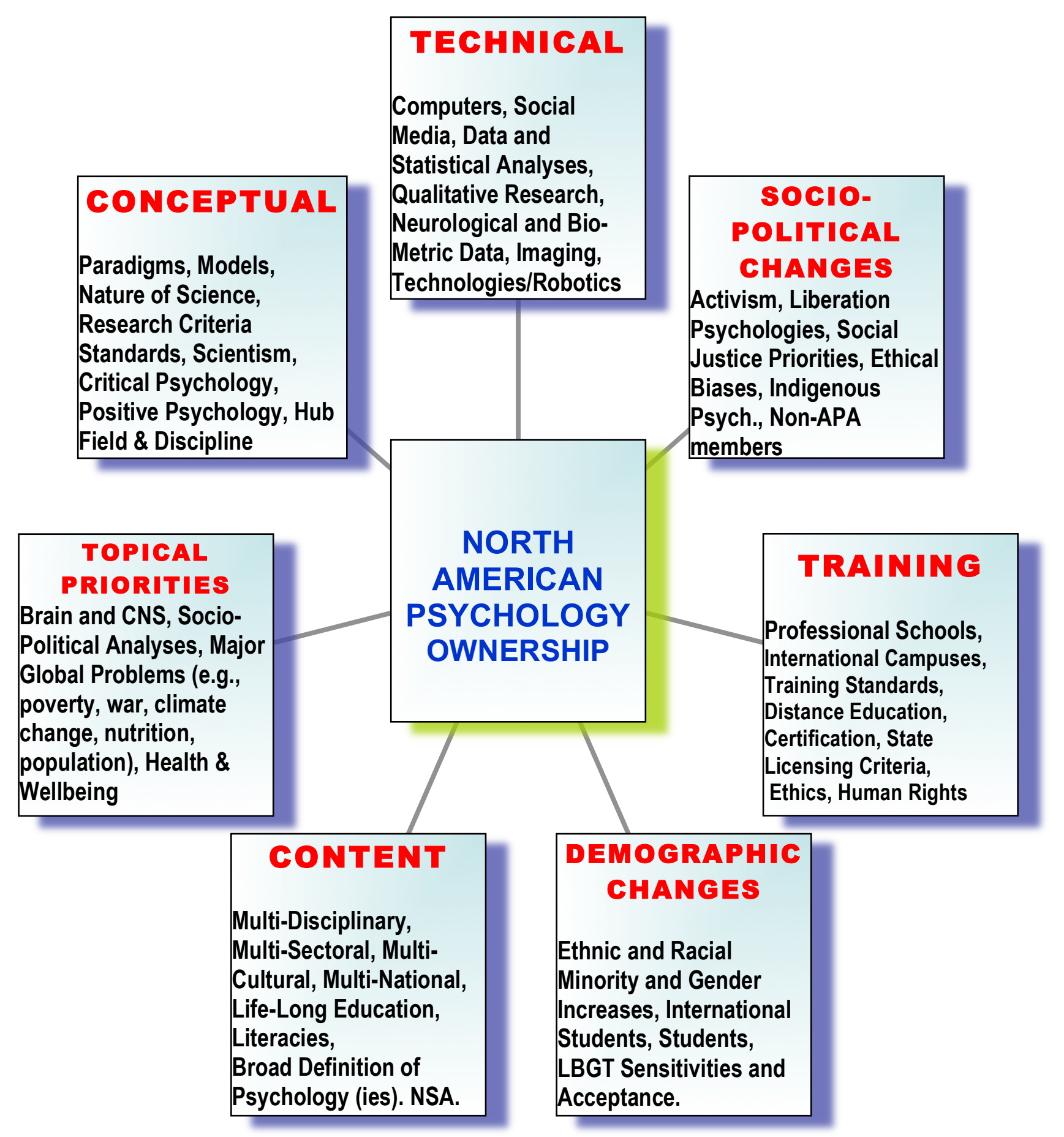

Chart 1: Graphic Display of Changes, Trends, and Challenges in North American Psychology 
The trends, changes, and challenges I cite are: (1) multiple; (2) simultaneous; (3) interactive; (4) dynamic, and (5) subject to internal and external events, forces, and people. In my opinion, the trends, changes, and challenges raise serious questions and issues about the need to "rethink" psychology (psychologies) and to "reconsider" traditional dominance of North American Psychology's history, assumptions, and consequences.

The "rethinking" and "reconsideration" is critical for the current "corporatization" model of the American Psychological Association. The corporate model, replete with its emphasis on hierarchical power, dominance, position, competition, and product, has come at the expense of compromising psychology's identity and purpose as an academic and professional discipline.

\section{Contexts for Abuses}

Psychology as a hub discipline or profession, extending its knowledge and application to distal areas, reveals both the importance of its study, and also its promise. This promise must not be betrayed. It must be nurtured, accountable, and transparent to inquiry and documentation. The Hub Model must not become a Western Hub unless it is recognized as such.

While many of the trends, changes, and challenges occurring in psychology are obvious and welcome (e.g., increase ethnic and racial minority student and faculty presence; altered gender profiles), it is their determination and interaction that requires attention and consideration. At issue is whether the dominant professional and scientific organization "governing" psychology at this time - the American Psychological Association - is in need of rethinking its roles, functions, and regulatory responsibilities.

Psychology is not a commodity to be owned and dispersed according to those in positions of power. A brilliant European psychology scholar one told me: "Psychology has betrayed its promise." This scholar was referring to the alleged ownership and arbiter of psychology by North American psychologists and their organizational powers and influences.

\section{Seven Categories ...}

For purposes of discussion, I have grouped the trends, changes, and challenges into seven categories. The boundaries of these categories are fluid and interactive rather than fixed and separate. They are offered for purposes of reflection and discussion regarding the forces and the consequences shaping psychology's unique identity perhaps self-appointed - identity as a profession and science in a global era challenging North American psychology's dominant and hegemonic position. 
All cultures have psychologies unique to their location, time, and history. We all lose if one psychology is permitted to dominate. Within North American psychology, there have been numerous reflexive efforts to respond to the changes of our times. However, there remains an inherent inclination within North American and Western European psychology to impose an imprimatur of its assumptions and validity. This denies the process and the nature of psychology as content and process in constructing reality within unique historical, geographical, cultural, and socio-political contexts of different people ... regardless of their national identity and membership.

The push to establish acceptance of a uniform definition and model of psychology by Western dominated national and international efforts, under the guise of facilitating communication and coordination, represents another well-intentioned, but ultimately destructive colonization of mind and behavior across the world. This encourages national and international security agency entry into psychology organizations, with eventual abuse and sacrifice of purpose and intent.

While it is clear Western culture, replete with its popular culture of individuality, materialism, consumerism, commodification, competition, celebritization, and technicophilia, is being imposed upon the world via USA economic, political, and military dominance, we face the risks of global homogenization, and with this, the loss of variation and diversity that is the very nature of life itself. As I wrote previously, an epic challenges of our global era is "homogenization versus multiculturalism." With the homogenization of culture comes mass control and dominance (e.g., Marsella, 2014).

Chart 1 is offered as a brief summary of the trends and changes occurring in North American psychology. The chart is offered to facilitate awareness of the complex simultaneous events, forces, and trends which separately, and as a group, require discussion, debate, and reconciliation. It is essential indigenous and non-Western constructions of psychology be encouraged, rather than subject to hegemonic imposition of North American and Eurocentric psychologies.

As numerous scholars have pointed out (e.g., Tod Sloan, Fathali Moghaddam), implicit with North American and Western Eurocentric psychologies are ontological, epistemological, and practiological assumptions about human behavior. Training nonWestern people in North American psychology, under the guise of "science" and identification with Western power, raises serious ethical questions about "colonization." The training is often inappropriate and inadequate for any who choose to return to their home nations.

The pursuit of homogenization in psychology, led by the American Psychological Association and allied Northern European organizations, must recognize their potentially pernicious consequences. Diversity in psychology is as critical as bio-diversity, environmental diversity, cultural diversity, and national diversity. Standardization must be understood for what is it is, and what is does, and there must be careful and 
considered informed consent, transparency, and accountability. If North American psychology - its knowledge, practices, and values, as represented in the APA or CPA, becomes a misused tool for nefarious purposes, their institutional functions and purposes must be re-thought. Decisions should be made with an understanding of global, national, cultural, and scientific and professional events, forces, and person.

In my opinion, the existing situation is resulting in the encouragement and support of the following: (1) ethnocentrically biased mental health assessments, services and interventions; (2) limited applicability of psychological knowledge to the daily-life circumstances and challenges of people in developing countries; (3) inappropriate training of international psychologists in the USA and Europe; (4) limited attention to issues of peace, conflict, and justice associated with Western hegemonic globalization efforts; (5) suppression of critical debate because of perceived and experienced power asymmetries; (6) hesitancy to address the social, political, and economic determinants of thought and practice because these are ignored or minimally addressed in Western universities and colleges; (7) acceptance of North American and Western European psychology as the "world standard" for research and practice in many national and international organizations (e.g. WHO, Red Cross); (8) efforts to establish special categories of psychological knowledge and practice (e.g., operational psychology) bordering on cooperation and alliances with government security agencies (i.e., the "weaponization" of psychology). In my opinion, the ethei continuing to dominate this North American psychology are driven by a commitment to the following:

1. Individuality - The individual is the focus of behavior. Determinants of behavior reside in the individual's brain/mind, and interventions must be at this level rather than the broader societal context.

2. Reductionism - Small, tangible units of study that yield well to controlled experimentation are favored.

3. Experiment-based Empiricism - An emphasis on experiments with controls and experiment group Psychological Studies (March 2009) 54:000-000 13 comparisons and uses of ANOVA analyses that often account for $5-10 \%$ of the variance, and this is considered "science." Lab studies are often favored over field studies.

4. Scientism - The belief that methods of the physical sciences can be applied similarly to social and behavioral phenomena, which results in spurious methods and conclusions that are inappropriate to the subject under study or that avoid studying certain subjects. 
5. Quantification/Measurement - "If something exists, it can be measured, said Edward Thorndike. Unless something under study can be quantified, it is not acceptable for study. This, of course, leads to "operationalism" as the standard for assessing concepts.

6. Materialism - Favors variables for study that have a tangible existence rather than higher order constructs -- I can see it and touch it under a microscope.

7. Male Dominance - Years of male dominance favors particular topics, methods, and populations for study - remember "involutional melancholia," the psychiatric disease of middle-aged women, or the labeling of transgender as an illness. While this is changing, we must be alert to its legacy.

8. "Objectivity" - Assumption that we can identify and understand immutable aspects of reality in a detached way, unbiased by human senses and knowledge.

9. Nomothetic Laws - Search for generalized principles and "laws" that apply to widespread and diverse situations and populations because of an identification and admiration for the physical sciences.

10. Rationality - Presumes a linear, cause-effect, logical, material understanding of phenomena and prizes this approach in offering and accepting arguments and data generation.

While these assumptions - characteristics - are now yielding to pressures from many different quarters (e.g., ethno-cultural, racial, and national groups, subjective/qualitative approaches, gender-equality, multi-disciplinary orientations), the ties to the logical positivism era remain. The salvation, even if this word may seem inappropriate, to this situation resides in prizing "doubt," not certainty. It is the adaptive dialectic (doubt and certainty) that enriches and extends our human possibilities and potential. A global era, now constricting in the face of nationalism, still requires a rethinking of psychology and its organizational manifestations, rather than a rigid adherence to unsuitable assumptions and practices (Marsella, 1998, 2012).

Even as we reach a hard won conclusion, doubt emerges to move us toward yet other possibilities. Unlike other beings whose behavior is fixed by reliance upon instinct and reflex, human beings have the capacity for reflective thought. We can reach a conclusion in one moment and modify it a moment later. The human impulse to know and to doubt provides an insight into the origins and nature of our . . . belief systems. These too, spring from our impulse to know and to doubt (Marsella, 1999). There is room for all, without imposing standards directed toward domination and control. The idea of setting standards for psychology across the world represents a "colonialistic" impulse - an inclination to subdue differences by relying a power residing in military, 
technological, and economic superiority, not moral, intellectual, nor historical and contextual foundations.

The salvation also resides in accessibility, transparency, and accountability in powerful organizations (e.g., APA). The tragedy of recent revelations regarding the alleged abuses by APA staff and members is only an "opening door" to the consequences of power asymmetries. It is the stuff of nations and world orders, and illuminates the mechanisms and pathways by which nation agendas can come to exact influence, control, and domination over knowledge and practice. Organization and institution collaboration must constantly be subject to scrutiny and evaluation. Reflexive participation by both all sides is essential, especially when a national security agency or government branch is involved, risking psychology's promise and potential for peace and justice. More is yet to come!

\section{Author contact information}

Anthony Marsella, Ph.D.

Email: marsella@hawaii.edu

\section{References}

Berger, P., \& Luckman, T. (1966). The social construction of reality: A treatise on the sociology of knowledge. NY: Anchor Books.

Huntington, S. (1996/2011). The clash of civilizations and the remaking of world order. NY: Simon \& Schuster.

Leong, F., Pickren, W., Leach, M., \& Marsella, A.J. (2011). Internationalizing the psychology curriculum: Foundations, issues, directions. NY: Springer SBM

Marsella, A.J. (1999). In search of meaning: Some thoughts on belief, doubt, and well being. The International Journal of Transpersonal Studies, 18, 41-52.

Marsella, A.J. (1998). Toward a global-community psychology: Meeting the needs of a changing world. American Psychologist, 53, 1282-1291.

Marsella, A.J. (2009). Some reflections on the potential abuses of psychology's knowledge and practices! Psychological Studies (National Academy of Science India), 1, 10-14 
Marsella, A.J. (2012). Globalization and psychology. Journal of Social Issues, 68, 454472.

Marsella, A.J. [December 1, 2014]. The epic ideological struggle of our global era: multiculturalism versus homogenization. Transcend Media Services www.transcend.org).

Misra, G. (1996). Psychological science in cultural context. American Psychologist, 51 , 496-503. 